\title{
The Role of Personality Traits in the Relationship between Organizational Structure and Job Satisfaction: An empirical study on rural organizations in EI-Behira governorate
}

\author{
Mohamed A. Elbardan. and Amir Mohamed Abdalla 1
}

\begin{abstract}
Theoretical and empirical relationships between organizational structure and job satisfaction have received a renewed considerable attention in the literature. Typically, empirical models of organizational behavior have related job satisfaction to the interaction of the sociopersonality characteristics of individuals and the internal characteristics of the organization. The purpose of this study is to test the hypothesis that some individual personality traits (such as motivation/achievement) play an intervening role in the relationship between organizational structure and job satisfaction.

The study was conducted in El-Behira governorate and random disproportionate stratified sample was used to determine the selected 4 districts ( Damanhour, kom Hamada, kafr eldwar and abo homos) and 8 villages were selected randomly 2 villages from each district. The data was collected by personal interviews from the top management at 48 rural organizations.Data was statistically analyzed by applying both simple regression and stepwise multiple regression.

Results show that the organizational structure is explaining about $29 \%$ from the variance of job satisfaction and motivation explains about $14 \%$ from the variance of job satisfaction. The study recommended that more attention should be paid to modelling short/long term structural plans according the skill variety, task identifying, task implication, autonomy and feedback framework. Finally the study suggests a several mechanisms for motivating employees as summarized here: 1-the institutional dynamics, 2- improving the work physical conditions, 3- involve employees in the formulating the skill variety, task identifying, task implication, autonomy and feedback frameworks,4- reward constructive classifications, and 5- clarifying the link between productivity and financial rewards.
\end{abstract}

\section{INTRODUCTION}

The work we do plays a dominant role in most people's life. Our work not only occupies more of our time than any other single activity, but also provides the economic basis for our lifestyle, and constitutes a central aspect of who we are, how we define ourselves as

\footnotetext{
${ }^{1}$ Researcher, Agricultural Extension and Rural Development

Research Institute. Dep. Of Rural Sociology, Egypt

Received August 2, 2007, Accepted October 8, 2007
}

individuals; That's from the side of employees, from the side of organizational development the theorists have attempted to systematically create work situations (physically and psychologically) that enhance employee's productivity, motivation, job satisfaction and commitment factors that may contribute to high levels of organizational performance [1].

In discussing the success or failure of specific organizations, theorists often refer to the important influence of job satisfaction and employee moral. The evidence for this claim on the rural Egyptian circumstances may be found in a study by Hassan, he suggests that organizational structure is related to the satisfaction through several key determinants; first, the organization's reward system is highly related to job satisfaction, this refers to how pay and promotions are distributed? Are employees paid adequately and fairly relative to other? A second organizationally based determinant of job satisfaction is perceived quality of supervision. Specifically, study has determined that satisfaction tends to be high when employees believe their supervisors are competent, have their best interests in mind, and treat them with dignity and respect [2].

Third, the study clarifies that job satisfaction is related to the decentralization of power. The decentralization refers to the degree to which the capacity to make decisions resides in many employees as opposed to just one central person. When power is decentralized many people are allowed to make decisions and they can freely participate in decision making. Such situations tend to promote a job satisfaction. A fourth determinant is the level of work and social stimulation, employees tend to be most satisfied with jobs that provide them with an overall work load and level of variety that are not so low as to boring and not so high to be overwhelming and unduly challenging. A fifth determinant of job satisfaction is pleasant working conditions. Results have shown that job satisfaction is reduced by overcrowded conditions, lack of facilities and the unsupportive work climate. Although these factors are not directly associated with 
the job satisfaction, but with the context in which the work is performed, they have been found to have a negative impact on job satisfaction [2].

\section{THEORITICAL FRAMEWORK}

A number of organization theorists concluded that human behaviour in organizations is a function of the interaction between two main variables. These are; personal individual characteristics, organizational structure and environment characteristics [2]. In this context, one can distinguish between two major types of human behaviour: (1) job satisfaction behaviour, and (2) performance behaviour.

Job satisfaction is the main focus of this study. It has been, and still is, the main focus of a considerable number of organization theorists. This is based on the assumption that satisfied employees perform better. That is to say, there is a positive correlation between job satisfaction and performance, which is the ultimate dependent variable in organizational behavior. This focus has not been limited to the theoretical study of the different aspects of job satisfaction - both cognitive and methodological - but many theorists also concentrated on the overt behavior as an external reflection for job satisfaction [3]

Satisfaction behavior has been studied from different aspects. These aspects represented an evolution of the methodology of studying satisfaction behavior, with the main aim of creating conceptual theories, and applicable rules that could represent guide lines to practitioners in this field. This cumulative research effort resulted in three distinctive dimensions of satisfaction behavior.

The first dimension deals with the nature and constructs of satisfaction behaviour. This dimension is based on the assumption that satisfaction is an emotional behaviour. Therefore, it depends on the psychological state of an individual, assuming that all psychological factors and variables are reflected in one dependent variable, i.e. satisfaction [4]

The second dimension takes us one step forward. It studies the psychological processes that result in satisfaction. In the sense, that satisfaction is the outcome of the interaction of various psychological factors.

The third dimension deals mainly with the behavioural aspects resulting from satisfaction. Therefore it concentrates on the correlation between satisfaction and performance, the degree of work stability (absenteeism, labour turnover), and dispute and conflict indicators (complaints, production limits) [4].

Therefore, to understand the general framework of satisfaction behavior, a general theoretical background of the determinants of satisfaction is briefly provided below:

\section{1-The Equity Approach}

The theories and models belonging to this point of view are based on the assumption that the perception of an individual to the equity and fairness of his returns determine satisfaction behaviour. That is to say, that there is a positive relationship between the perception of equity and the degree of job satisfaction. Therefore, job satisfaction is the outcome of a social comparison process, and depends on the perception of equity in that context [5].

One of the most prominent theories in that field; is the Equity Theory where a lot of organization behaviour theorists tend to agree with its basic philosophy. The main assumption of this theory states that; there is an exchange relationship between the individual and the organization. Individuals provide inputs such as their experience, skills, abilities, and attitudes. In return, they obtain outcomes such as income, social status, and other benefits. The theory states; that individuals compare the ratio of their outcomes to their inputs with the same ratio for others that might be perceived as an appropriate base for comparison. Satisfaction results if, and only if, both ratios are equal. However, if this equilibrium is disturbed, feelings of frustration and tension are generated, which negatively affect job satisfaction, and hence, performance [6].

Lawler who tried to find out the determinants of job satisfaction provides another theoretical model. The main idea of the model is that satisfaction is the result of comparing actual outcomes with perceived deserved outcomes. Lawler assumed that there are three types of feelings depending on the results of the comparison; these are satisfaction, dissatisfaction, and guilt [7].

The implied meaning in the previous models is that individuals are not after the absolute maximisation of their outcomes. Instead, they are after what they might perceive as a 'fair outcome'. The implied assumption here is that there is an ethical value that makes individuals pursue a fair distribution of outcomes, and makes people suffer from guilt or 'sheepishness' when they get more than their fair share, and frustration and grievance when they get less [8].

Even though, the results of many empirical studies tend to support the equity point of view in interpreting job satisfaction [9], they suffered from major flaws that might allow some counter arguments as follows:

First, many of the concepts presented by the equity point of view lack an operational definition that gives them an empirical meaning, and provides consensus upon the study of such concepts. As an operational 
definition describes a concept by explaining the behavioural situations in which it appears. Therefore, it provides empirical processes and procedures that are employed for measurement purposes, rather than concentrating on the literal meaning of a concept. The absence of such operational definitions makes the measurement process almost impossible. In addition, it undermines the empirical importance of these studies as they lack 'methodological rigor'.

Second, the equity approach was limited in its interpretation of job satisfaction to the equity criterion. However, there might be other factors, in addition to equity, which influence job satisfaction such as the extent to which job outcomes satisfy the needs of an individual. It might seem apparent that the relationship between the previous two factors is one of mutual influence [9].

Third, both Adams' theory and Lawler's model concentrated on comparisons an individual makes with others. However, the feelings of equity are not only generated as a result of comparison with others. An individual might compare his job outcomes to selfstandards such as his previous experiences, or system referents, and future promised outcomes that made him accept the job in the first place [10].

Fourth, Adams stated that when the result of the comparison is in favour of the individual, a feeling of guilt results. However, the results of many empirical studies seem to contradict this statement. Individuals tend to overstate the value of their input, and understate the value of their outcomes.

In addition, the feeling of guilt is easily overcome, manipulated, and interpreted in many ways. History does not provide us with a lot of examples of people who gave up their jobs because they got more than their fair share, or because their outcomes were a lot more than peers who provided the same input.

Fifth, the equity approach ignored the effect of variables relating to individual and/or situational differences on the perception of individuals of the comparison between the actual and the expected outcome. That is to say, that individual differences in personality, previous experiences, motives, and attitudes might influence the attitude of an individual towards work. Moreover, individuals who are outcome-oriented tend to suffer from more tension and psychological reactions than those who are input-oriented in case of overpayment [11]. Moreover, the negative psychological effects tend to be lower in large size organizations, where personal relationships are minimal, as well as personal interaction between individuals, and hence there is a lack of the necessary information for the purpose of outcome/input comparison [12].

\section{2- The Aspiration Approach}

The main idea here is that satisfaction behaviour is determined through an evaluation process and/or selfcomparison between the aspired outcomes of an individual, and his perception of his actual outcomes. Satisfaction, therefore, is a function of the difference between perceived actual outcomes and aspired or expected outcomes. The more the level of actual achievement is equal to, or exceeds, expectations the greater the satisfaction, and vice versa [5].

A group of empirical studies might form what is known as the Level of Aspiration Theory. The most prominent of which, are briefly explained below:

The work of Atkinson (1964) may be considered one of the first attempts to interpret job satisfaction based on the level of aspiration. His major contribution was that individuals analyse their previous achievements sequentially, and compare them to their expected outcomes. The result of the comparison is the main determinant of satisfaction as previously explained [13].

Locke provides another theory based on aspiration. In his analysis of the relationship between job satisfaction, performance, and goal-setting, he bases his analysis on two cognitive dimensions: (1) the aspired level of goal achievement (situations, issues, incentives, etc.), and (2) value content, which represents the needs and wants that lie within the perceived environment of an individual. This set of needs and wants naturally changes through time, also according to differences in experiences and previous levels of achievement [14].

According to Locke, job satisfaction is determined by the difference between the aspired level of achievement resulting from work, and the actual achieved value content, as well as the personal subjective valuation of this value. Therefore, the relative importance of value content determines the effect of the difference between aspiration level and value content on job satisfaction.

Despite the fact that a number of empirical studies support the aspiration approach, there are a number of counter arguments that are briefly explained below:

First, both goal setting and aspiration level theories are based on the assumption that human behaviour, and motivation, is goal oriented. However, none of them went as far as to explain the determinants of goal attractiveness and acceptance, and/or the determinants of individual commitment towards goal achievement. As not every goal is directly linked to a behaviour, and for a goal to be translated to behaviour various factors need to be considered, such as; the degree of goal-consistency with other objectives of the individual, the degree of valence of an individual to the outcomes of a certain 
behaviour, and the degree of expectancy that outcome achievement is dependent upon behaviour. Therefore, one might conveniently conclude that the aspiration point of view lacks the ability to provide a complete and integrated explanation that interprets satisfaction behaviour [3].

Second, the aspiration point of view provides over generalised judgements, concerning the way satisfaction behaviour is generated, which might not be applicable to all jobs in different contexts. As specialisation and division of labour result in a high degree of job interaction and task interdependence. Consequently, the process of goal setting, and hence the measurability of goal achievement, for each job becomes very difficult, if at all possible. In this context, it is very unlikely to be able to determine the degree of job satisfaction as a function of the difference between actual and aspired achievement [15].

The previous conclusion also applies to some administrative and clerical jobs, where it becomes difficult to express objectives in clear measurable levels. Also, in the case of jobs with predetermined highly mechanistic procedures and regulations, where the freedom off individuals is highly controlled.

Third, even if determining the goal-setting process is possible for a particular job, this does not necessarily mean that it is identical, or even similar, for all the individuals that occupy the same job. This is because individuals differ in personality traits, needs, attitudes, social status, and so on, which influences the reactions of individuals towards the goal-setting process and participation in goal formulation, and hence the resulting satisfaction [16].

Fourth, the aspiration point of view ignored the psychological processes that formulate the feeling of outcome equity, which is represented by the comparison of the outcomes of an individual with others. It is worth

mentioning, in this context, feelings that result from an internal comparison (between actual and aspired achievement), differ in nature from those resulting from an external comparison (between an individual and others) [7].

\section{HYPOTHESES OF THE STUDY}

The main assumption of this study is that the effect of organizational structure on job satisfaction depends on the personality traits of individuals. Two hypotheses were designed to investigate the intervening role of personality traits in the relationship between organizational structure and job satisfaction. relationship between organizational structure and job satisfaction.

H1: Achievement may affect the relationship between organizational structure and job satisfaction.

H2: Motivation may affect the relationship between organizational structure and job satisfaction.

\section{METHEDOLOGY}

A: Sampling Design: The study was conducted to investigate the role of individual personality traits in the relationship between organizational structure and job satisfaction at 4 districts in El-Behira governorate. The random disproportionate stratified sample was used to determine the selected villages' from-Behira governorate: whereas 4 districts were selected Damanhour, kom Hamada, kafr eldwar and abo homos. And two villages from each district were randomly drawn as follows: sanhour and alkhazan from damanhour, altod and saft alenab villages from kom Hamada district, zohra and kom elberka from kafr eldwar and finally; besentway and demesna from abo homos district. And all of their rural organizations were selected to represent the sample of this study. Therefore; the sample of study consists of 48 of top management employees of the selected organizations as showed in table (1).

B: Measurements: The study employed organizational structure as an independent variable that was measured by the job characteristics model JCM developed by Hackman and Oldham [17] along five dimensions, which are:

\section{Table 1. the sampling frame}

\begin{tabular}{lc}
\hline \multicolumn{1}{c}{ Organizations* $^{*}$} & total \\
\hline The local units & 8 \\
The agricultural cooperatives & 8 \\
The bank of credit and development & 7 \\
The community development board & 6 \\
The health unit & 8 \\
The vet unit & 7 \\
The extension centers & 4 \\
\hline total & 48 \\
\hline
\end{tabular}

each organization was represented by the top management employee 
1- Skill variety: refers to the extent to which a job requires a number of different activities using several of the employee's skills and talents. Skill variety includes 3 items: (a) the range of skills, (b) the diversity of work missions and (c) the dispensation of human skills.

2- Task identify: refers to the extent to which a job requires completing a whole piece of work from beginning to end. Task identify was measured by 4 items: (a) the mission diagnosis, (b) the task logistics, (c) the task processing and (d) the accomplishment.

3- Task Significance: refers to the degree of impact the job is believed to have on other people, either within the organization or in the world at large. Task identify includes 3 items: (a) the confidence of job configuration, (b) the trust of job modules and (c) the credibility of job outcomes.

4- Autonomy: refers to the extent to which an employee has the freedom and discretion to approach his job perfectly. Autonomy was measured by 3 items: the employee independence in (a) planning, (b) scheduling and (c) task activating.

5- Feedback: refers to the extent to which the job allows people to have information about the efficiency of their performance. Feedback includes 4 items: (a) feedback framework design, (b) inter communication channels, (c) information flow and (d) the circulation of results and information.

The all 17 items (constructing the organizational structure scale) were measured by formulated answers; strongly agree, agree, neutral, disagree and strongly disagree (weighed from 5 to 1 respectively).

Intervening variables relating to personality traits involved the need for achievement, and the need for motivation. These were measured using the personality research form (PRF) developed by Jackson [18].

Firstly: achievement was measured by 7 components:

1- Tendency to the work.

2- The productivity.

3- Created responsibility.

4- Time- urgent attitude.

5- Seriousness in work.

6- Coping with barriers.

7- Impatient behaviour. Whereas all 7 items were measured by the answers; strongly agree, agree, neutral, disagree and strongly disagree (weighed from 5 to respectively).
Secondly: motivation in this study is defined as the set of processes that arouse, direct and maintain human behaviour toward attaining a goal. The motivation scale was measured by 3 parts:

1- Arousal: includes3 items: (a) the need for work, (b) the relative importance of the wage and (c) the willingness to attain a certain goals.

2- The direction: includes 3 items: (a) the perception of the choices, (b) the priority of attainment and (c) the capability to attain the selected goal.

3- The maintenance: includes 2 items: (a) the persistence behaviour toward the goal and (b) the continuance of directing toward meeting the goal. All the 8 items were measured by the answers; strongly agree, agree, neutral, disagree and strongly disagree (weighed from 5 to 1 respectively).

Job satisfaction (the dependent variable) was measured by using an adapted version of the University of Minnesota method commonly known as the job description index (JDI). (JDI) is primarily concerned with attitudes about five dimensions:

1- The work itself.

2- Pay.

3- Opportunities.

4- Supervision.

5- People (coworkers). The Job satisfaction was measured by 5 answers; extremely satisfied, satisfied, neutral, dissatisfied and extremely dissatisfied (weighed from 5 to 1 respectively).

C: Data collecting: The questionnaires were pre-tested and collected by personal interviews on April 2007.

D: Statistical Techniques: Stepwise regression was applied to investigate the relationship between Job Satisfaction, Personality Traits (both; achievement and motivation) and organizational structure.

\section{RESULTS}

To estimate the relationship between Job Satisfaction and organizational structure simple regression model was used. As showed in table (2) correlation coefficient was 0.541 and $F$ value 19.15 and it's significant at 0.01 , $\mathrm{R}^{2}$ value was 0.293 meaning that the organizational structure (as independent variable) explains about $29 \%$ from the variance of job satisfaction (as dependent variable).

Stepwise multiple regression model yielded a reduced equation containing 2 variables and explains $43 \%$ from the variance of job satisfaction (as dependent variable) and the achievement variable was excluded from the equation. Table (3) 
Table 2. the simple regression analysis

\begin{tabular}{lcrcc}
\hline \multicolumn{1}{r}{ The independent variable } & Beta & t & Sig. & $\mathbf{R}^{2}$ \\
\hline The organizational structure. & 0.541 & 4.635 & 0.000 & 0.293 \\
$\mathrm{r}=0.541$ & \multicolumn{2}{c}{$\mathrm{F}=19.15^{* *}$} \\
\end{tabular}

Table 2. the stepwise multiple regression analysis

\begin{tabular}{lcccccc}
\multicolumn{1}{l}{ The independent variable } & Beta & t value & Sig. & \multicolumn{2}{c}{$\mathbf{R}^{2}$} \\
\cline { 3 - 7 } & & & & change & Accum. \\
\hline The organizational structure. & 0.418 & 5.103 & 0.000 & 0.291 & 0.291 \\
Motivation. & 0.341 & 3.712 & 0.014 & 0.138 & 0.429 \\
Multiple $\mathrm{R}=0.655$ & & $\mathrm{~F}=23.21 * *$ & & \\
\hline
\end{tabular}

clarified that: multiple correlation coefficient was 0.655 and $F$ value 23.21 and it's significant at $0.01, R^{2}$ value was 0.429 which means that the organizational structure and motivation (as independent variables) explain $43 \%$ from the variance of job satisfaction (as dependent variable).

The independent variables were ranked as follows: the organizational structure variable explains $29 \%$ of the variance in the dependent variable, and motivation variable explains about $14 \% \%$ of the variance of job satisfaction (as dependent variable).

\section{CONCLUSION}

The findings of this research reveal the effect of personality traits, as intervening variables, on the relationship between job characteristics and job satisfaction to those who are oriented towards motivation. On light of the result of the current study quite a few mechanisms for motivating employees should be addressed on the rural organizations regarding the job satisfaction and the key ones are summarized here:

○ the institutional dynamics,

o improving the work physical conditions,

○ involve employees in the formulating the skill variety, task identifying, task implication, and autonomy and feedback frameworks,

- reward constructive classifications, and

- clarifying the link between productivity and financial reward

Regarding to the motivation; the study also suggests the job redesign model for the effectiveness of the rural organization in Egypt, this model includes three techniques:
1- job instrumental model: An approach taken by organizations toward job enhancement, which specifies that five core dimensions (skill variety, task identifying, task implication, and autonomy and job feedback) produce critical psychological states that lead to beneficial outcomes for individual ( high job satisfaction) and the organization(high performance).

2- Job enlargement: the practice of expanding the content of a job to include more variety and a greater number of tasks at the same level.

3- Job enrichment: the practice of giving employees a high degree of control over their work and responsibility from planning and organizing through implementing the jobs and evaluating the results.

\section{REFERENCES}

[1] Bass, B., "Social behaviour and the orientation inventory: A review", Psychological Bulletin, 83, 1997.

[2] Hassan, A. M. "The Effect of the Congruence between the Individual Lifestyle and the Organization Structure on Job Satisfaction", PhD. Thesis, Nottingham Trent University- Southampton Institute, 2002.

[3] Sells, S., "An interactions looks at the environment", American Psychologist, 48, 1993.

[4] Porter, L., R. Steers, R. Mowday, and P. Boulian, "Organizational commitment, job satisfaction, and turnover among psychiatric technicians", JAP, 69, 1989.

[5] Porter, L., and R. Steers, "Organizational commitment, and personal factors affecting 
employee absenteeism", Psychological Bulletin, 75, 1988.

[6] Adams, J., "Inequity in social exchange", Advances in experimental social psychology, NY Academic Press, NY, 1965.

[7] Lawler, E., "Pay and organizational effectiveness: A psychological view", McGraw Hill, NY, 1973.

[8] Adams, J., and W. Rosenbaum, "The relationship of worker productivity to cognitive dissonance about wage inequities”, JAP, 56, 1972.

[9] Thomas, D., "Beyond Performance and Satisfaction: A Review", JMR, 78, 1997.

[10] Goodman, C., "Does life style really matter: Friedlander's model revisited", JAP, 89, 1997.

[11] Tornow, W., "The development and application of input-outcome moderator test on the perception and reduction of inequity", Organizational Behavior and Human Performance, 6, 1991
[12] Campbell, J., and R. Pitchard, "Motivation theory in industrial and organizational psychology", Handbook of Industrial and Organizational Psychology, Rand McNally, Chicago, 1996.

[13] Atkinson, J., "An introduction to motivation", Princeton, NJ, 1964.

[14] Locke, E., "Toward a theory of task motivation and incentives", Organizational Behavior and Human Performance, 7, 1976

[15] Baulmer, J., "Defined criteria of performance in organizational control", ASQ, 36, 1995.

[16] Latham, G., and Y. Stoppleare, "A review of research on the application of goal setting in organizations", AMJ, 38, 1995.

[17] Hackman, J., and G. Oldham "Development of the job diagnostic survey", JAP, 60, 1975.

[18] Stone, H., M. Togner, and S. Panomi, "Job characteristics, personality traits, and job satisfaction", Human Relations, 10, 1981. 


\section{الملخحص العربي}

\section{دور السمات الفرديه في تحديد العلاقه بين البناء التنظيمى والرضا عن العمل: دراسة ميدانية للمنظمات الريفية في محافظة البحيرة}

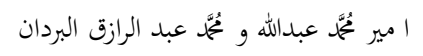

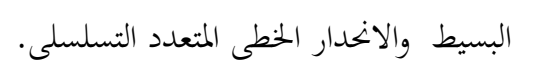

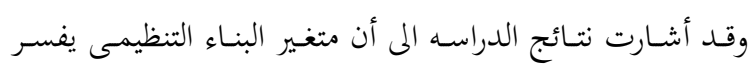

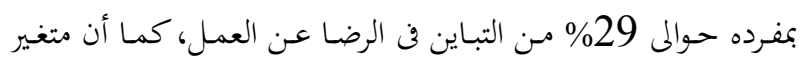

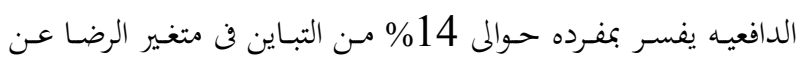

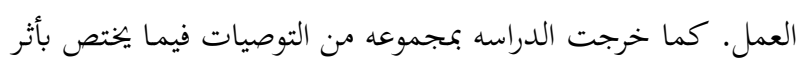

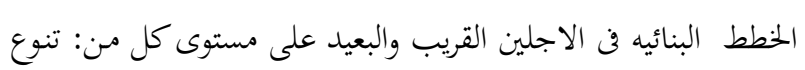

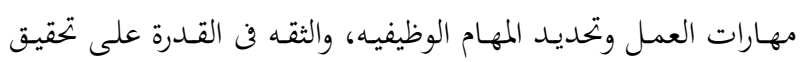
مهـام العمله، ودرجـه الاستقلاليه فن آداء الادوار الوظيفيه، واخسيرا

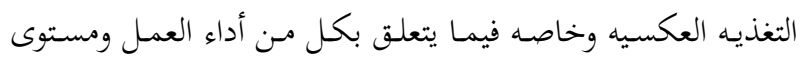

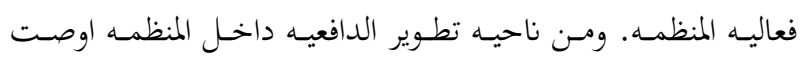
الدراسه بمجموعه من الآليات كما يلى :1- الديناميه المؤسسيه، 2-

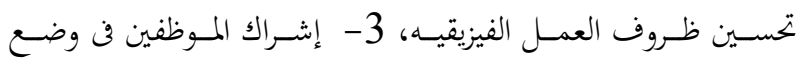

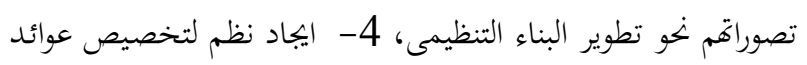

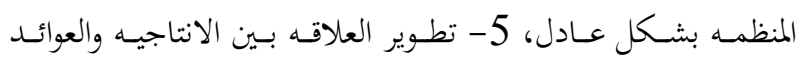

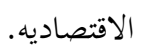

تشـكل العلاقه بين البنـاء التنظيمى والسـلوك الانسـانف داخلـ

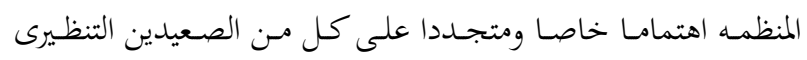

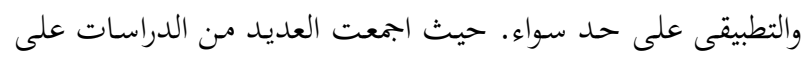

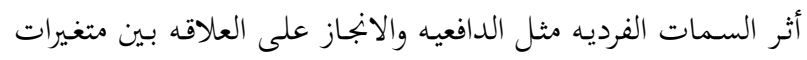

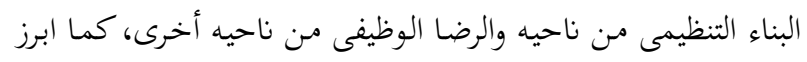

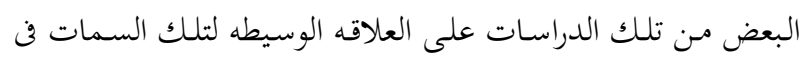

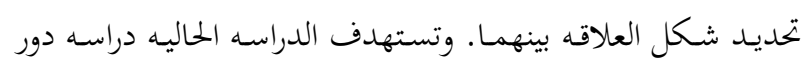

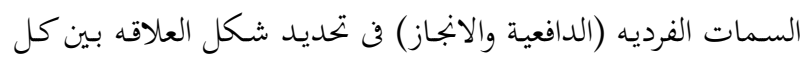

$$
\text { من البناء التنظيمى والرضا عن العمل في المنظمات الريفيه. }
$$

ولقد اجريت الدراسه بمحافظه البحيرة حيت تم اختيار 4 مراكز

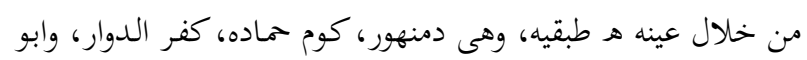

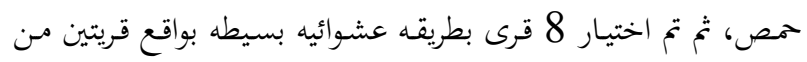

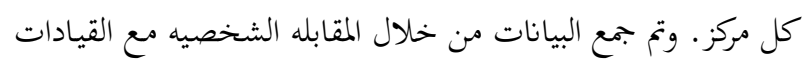

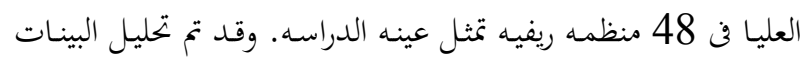
احصائيا اعتمادا على كل من الانحدار 